\title{
Erratum to: The impact of treatment compliance on fracture risk in women with breast cancer treated with aromatase inhibitors in the United Kingdom
}

\author{
Nina Schmidt ${ }^{1} \cdot$ Louis Jacob $^{2} \cdot$ Robert Coleman $^{3} \cdot$ Karel Kostev $^{1}$ • \\ Peyman Hadji ${ }^{4,5}$
}

Published online: 10 May 2016

(c) Springer Science+Business Media New York 2016

\section{Erratum to: Breast Cancer Res Treat (2016) \\ 155:151-157 \\ DOI 10.1007/s10549-015-3661-3}

In the original publication of the article, the first author name was misspelt as "Nina Schimdt". The correct name of the author should read as "Nina Schmidt" as given in this erratum.

The online version of the original article can be found under doi:10.1007/s10549-015-3661-3.

Karel Kostev

kkostev@de.imshealth.com

1 IMS HEALTH GmbH \& Co. OHG, Epidemiology, Real World Evidence Solutions, Darmstädter Landstraße 108, 60598 Frankfurt, Germany

2 Department of Biology, École Normale Supérieure de Lyon, Lyon, France

3 Department of Oncology, University of Sheffield, Sheffield, UK

4 Nordwest Hospital, Frankfurt, Germany

5 Department of Gynaecology, Gynaecological Endocrinology and Oncology, Philipps-University of Marburg, Marburg, Germany 